\title{
Research on Model Innovation of Higher Education under the Background of the Sharing Economy
}

\author{
Huang Liumei ${ }^{1,2}$ \\ ${ }^{1}$ Guilin Tourism University, Guangxi Guilin, 541006, China \\ ${ }^{2}$ Saint Paul University, Tuguegarao City, Cagayan Province, Philippines, 3500
}

Keywords: Higher education, Sharing economy, Model innovation

\begin{abstract}
In recent years, the upsurge of the sharing economy has swept all sectors of the society. The sharing economic model of colleges and universities is a new form of dissolving the scarcity of resources, saving the cost, promoting the equity of education and surpassing the traditional economic model. From the perspective of the sharing economy, the model of higher education has the problems of insufficient sharing awareness, single sharing products and deficient sharing system. In view of these problems, the corresponding solutions are put forward to provide some references for the relevant researchers.
\end{abstract}

\section{Introduction}

The sharing economy generally refers to a new economic model based on the temporary transfer of the right to use the goods based on strangers and to obtain certain rewards as the main purpose [1]. The essence is the idle goods, labor and education and medical resources under the line of integration. Some also say that the sharing of the economy is a fair share of social resources, each in different ways to pay and benefit, together to gain economic dividends. The sharing economy is achieved through the internet as a medium [2]. The sharing economy will be the most important force in the social service industry. In the areas of housing, transportation, education services, life services and tourism, excellent sharing economic companies are emerging: from pet sharing, parking sharing to expert sharing, community service sharing and tour guide sharing. The new models emerge in an endless stream of resources under the supply - side integration line and provide more quality experience for the users at the demand side. The impact and penetration of the shared ideas, as well as the storm, shook the whole world of education. For higher education, education resource sharing refers to the full coordination and play various units, departments, universities and between various colleges and universities, the common use of educational resources, teacher resources, such as winter sports resources, library resources, network resources, data resources of each experiment set. The greatest benefit of such sharing is that the utilization of educational resources has been improved on the premise of less or no increase in educational input. Sharing educational resources in Colleges and universities is a systematic and big project. At the macro level, the operation of such a large project requires a complete set of incentive mechanisms and performance evaluation mechanisms. On the specific operation level, we need unified and standardized access technology parameters, and establish a reasonable organization startup mechanism to fully mobilize the enthusiasm of all colleges and universities to participate in sharing.

\section{Shortages of Higher Education Models from the Sharing Economy Perspective}

\subsection{Insufficient Sharing Awareness}

Influenced by the concept of traditional universities and the bondage of departmentalism, self-sealing and traditional outdated ideas, most universities in China only focus on their own interests, and lack of overall awareness and planning in the process of construction [3]. This kind of 
self - administration will cause the low level of construction and waste. In addition, the traditional colleges and universities adhere to the emphasis on professional, despise the humanities, pay attention to theory and despise practice, and imprison the smooth development of educational resources sharing activities. At present, although China's provincial government bears most of colleges and universities management responsibilities, but the core of the management system of higher education is still the central, the central administrative measures taken by the remote control at all levels of colleges and universities, the rights of local government lost a serious impact on resource sharing decision making, restricting the realization of resource sharing. In addition, the "administration" management features of Chinese universities are obvious. The allocation of internal resources also needs to be examined and approved at various levels, and the administrative process is cumbersome and complex, which largely dispel the enthusiasm of university teachers and students for resource sharing. In addition, the interior is also between each other has been the lack of fight the enemy separately, exchange and communication, have long formed their own management mode, therefore, the lack of unified and effective management system, the system is difficult to achieve coordination and cooperation overall, causing the internal resources of colleges and Universities to rational use, to achieve resource sharing mode. The relatively sufficient educational resources and sharing platform are the necessary conditions to realize the sharing of resources. The lack of a suitable and effective sharing platform and technical support will lead to serious resource duplication. At present, there has been no systematic theoretical and practical guidance, which leads to the delay of cooperation and sharing. The long-term self-governance and relatively closed management construction result in the limited openness, interoperability and sharing of resources in schools, resulting in the fact that the resources of all colleges and universities cannot be truly shared due to platform problems.

\subsection{Single Sharing Products}

With the development of the domestic university city construction scale and the establishment of some local colleges and universities union, the sharing of resources of higher education has made some achievements, but overall, the sharing content of different educational resources is still not rich enough, and the sharing level is still relatively low [4]. The specific performance is: the internal sharing of colleges and universities and the less sharing among schools. There are more opportunities for teachers to share and fewer opportunities for students to share. It was from the social aspects of the criticism and criticism, the public and university teacher's cadre's resources of ten universities have been put into operation the sharing situation is not satisfied, for the idle state resources and waste opinions. Only university students realize the circulation of the card, library resources, living facilities are not truly shared. In fact, at present, most of the winter university libraries in China are still borrowing books from students' certificates and teachers' certificates, which is not enough for the society to open, let alone the high cost and meticulous educational facilities in the laboratory. The cause of this situation is diverse, the main reason is from the internal of the university. Half of the universities think that resource sharing will weaken the economic interests of the university, and it is difficult to get the corresponding return from the common body. It is because of the lack of internal drive force that the sharing of educational resources in China's colleges and universities has been hovering at a lower level of cooperation. At present, network technology and digitalization technology have been widely applied in the construction of university library.

\subsection{Deficient Sharing System}

From the management perspective, the essence of higher education resources sharing through the breakthrough time and space constraints, will be relatively independent of each other in colleges and universities and education system of organic produce Luan, contact and interaction between independent and the size of the system, effectively realize the sharing of resources. In the era of Internet, it is not difficult to break through the boundaries of time and space, but it is difficult to realize the integration and interaction of the system on this basis. To break through the boundaries of time and space, and to combine the independent institutions of higher education and the educational 
system with each other needs to be guaranteed by system and policy. China's colleges and universities play the role of the government affiliated institutions and lack the initiative of running a school. If we want to truly realize the sharing of higher education resources, it will inevitably touch the existing educational system and management system. And the reform of the system involves many problems, and it is difficult to achieve the expected effect in the short term. Although the state attaches great importance to the sharing of higher education resources, but because our educational management system divides higher education resources into state ownership, colleges and universities only exercise the right to use educational resources. Therefore, the corresponding educational resource sharing supporting policy is always in the state of not much, if any. This also affects the implementation of institutions, fees and other measures in the process of sharing educational resources, which seriously hinders the development of the sharing of higher education resources. In addition, in the development of high quality educational resources, we should focus on the development of quality rather than quantity. We should actively explore the construction of multi-level, multi type high-quality educational resources, and establish and improve the mechanism of intellectual property protection. We need to establish a platform to really facilitate the sharing of educational resources. We should not only improve and update the content of the shared platform, but also achieve compatibility between the intercollegiate and corresponding databases and platforms. It is also necessary to standardize and integrate the database and platform, and facilitate the inquiries between teachers and students between different schools, and maximize the efficiency of the resource sharing platform.

\section{Innovation Strategies of Higher Education Models under the Background of Sharing Economy}

\subsection{Strengthen Sharing Awareness}

Colleges and universities should establish a global concept of openness and cooperation, cultivate awareness that they are good at promoting their own development from other brotherhood institutions, and change the old concept of traditional self-development. Sharing economy not only saves educational resources, but also improves the efficiency of educational resources utilization. It really realizes the healthy development of higher education and has far-reaching significance for the overall development of higher education in China. At the same time, colleges and universities should combine their own characteristics and advantages to cultivate educational resources that reflect the characteristics of our school. We should take the interests of all interests as the starting point to achieve the optimal allocation of educational resources. Basically, built their own book campus network, but there is still a big gap between the development of regional digital education and teaching resources sharing platform, compared with the academic libraries in developed countries. During the period of 13th Five-Year is an important period of strategic opportunities for information technology to lead the overall innovation, build new advantages of country competition, is our country towards network power from the network power, to become a global leader in Internet information technology is the key window period, from now ran and ran, leading the competition for period to seize the strategic high ground, but also the depth of economic and social informatization and for the full release of the new period of energy cooperation, we must strengthen the overall planning, active adaptation and lead a new round of revolution. The information sharing teaching resources platform construction should uphold the development concept of sharing, resource sharing platform construction break consciousness is relatively weak, cooperation consciousness is not strong state. To guide the university to the competition and cooperation of government departments, completely break set up the new education idea parochial prejudice, open, build, sharing, win-win. There is a competition between the two schools, and there is a certain interest agreement. Through policy, administration, funding and other measures, we actively build a new modern cooperative education system. 


\subsection{Expand Sharing Products}

Colleges and universities to implement regional education resources sharing can take advantage of resources for adjacent schools have to make up for each other, education resources shortage, the number of regional education resources to achieve amplification effect, so that long-standing shortage of resources in higher education or alleviate the problem in a certain extent. Due to the adoption of regional higher education resources sharing can make higher education resources are simultaneously amplified in quantity, time and space, discipline, etc., to produce all kinds of benefits superimposed effect which will lead to the quality and efficiency of higher education institutions is correspondingly enlarged; resources of higher education to implement regional shared benefits also showed low amplification the cost of education resources can make the regional education resources get ahead of future earnings, so the quality and efficiency of higher education has been enlarged, namely education resources input-output optimization. The benefits of online education are not only lower than the line can better fulfill the zero-distance timely interaction behavior between educators and students, and between teachers and students to communicate more convenient, more knowledge sharing and discussion in this all produced, accelerate the speed of knowledge updating and iteration. The corresponding and learning related data, such as online learning and discussion, can be recorded in a complete and timely manner to form a variety of learning flow data.

\subsection{Formulate Sharing Systems}

The sharing of educational resources in Colleges and universities is a systematic project, involving all aspects, and needs coordination and management. Establishing relevant and perfect educational policies and implementing a complete and scientific sharing mechanism can mobilize all positive factors, break all kinds of fetters and restrictions, and enhance the enthusiasm of universities to participate in sharing. Specifically, establish and implement a unified and strong leadership consultation mechanism, regularly held a joint meeting to solve problems, coordinate the relationship between the parties to follow the rules of the market operation, the establishment of economic accounting and cost subsidy mechanism, reasonable benefit mechanism of flat establish reward system, used to reward or punishment in the process of sharing units and departments and personal. We should improve and improve relevant policies and regulations, and provide legal support for the implementation of sharing. Education departments should actively guide the colleges and universities to establish and strengthen the consciousness of sharing, to make college fundamentally realize the sharing of educational resources is not only the effective way to realize the higher education transformation and upgrading, break through the stage of the bottleneck of the development of higher education in our country, but also the future development trend of higher education. This scientific and rational allocation of resources is not only of great significance to the development of the country's overall education, but also to the development of colleges and universities themselves. The sharing of higher education resources is a win-win strategy. Therefore, the relevant departments should actively advocate, guide colleges and universities to set up a high pattern and vision and make a wise choice. In the context of the market economy, it is indeed unrealistic to require universities to share unpaid and unreserved resources. We should meet the needs of certain economic benefits in Colleges and universities according to the actual situation to effectively stimulate the enthusiasm of universities to participate in the sharing of Featured high-quality educational resources, and promote the deep development of the sharing of higher education resources.

\section{Conclusions}

The innovative education under the shared economic model is a new model in the internet era and a new thinking to solve the problem of educational equity. As a new economic model, sharing economy in the global spread of university should quickly share economic dividend and repay the society, improve the management level and investment benefit to provide better support and services for the construction of an innovative country. 


\section{References}

[1] Zhang Chengen. Study on the Development of Higher Education from the Perspective of Sharing Economy [J]. Journal of Zhongzhou University, 2017, 34(6): 99-102.

[2] Zhao Yuru. A research on the management of valuable instruments and equipments in university under the mode of sharing economy [J]. Journal of Zhejiang University of Technology (Social Science), 2017, 16(3): 343-347.

[3] Haoyue Dong. Study on the Sharing of Municipal Higher Education Resource under Low-carbon Economy Perspective [J]. Meteorological and Environmental Research, 2013, 4(2-3) : 12-14+17.

[4] Zhu Wenyi. Discussion on Accelerating the Construction of Regional Digital Education and Teaching Resource Sharing Platform in Local University Libraries - Take Baicheng Normal University as An Example [J]. Journal of Baicheng Normal University, 2017, 31(5): 86-89. 